\title{
Double-blind comparative study of the antidepressant, unwanted and cardiac effects of minaprine and amitriptyline
}

\author{
J. GUY EDWARDS,${ }^{1}$ TIMOTHY G. DINAN, ${ }^{2}$ DEREK G. WALLER ${ }^{3} \&$ STEPHEN G. GREENTREE ${ }^{4}$ \\ ${ }^{1}$ University Department of Psychiatry, Royal South Hants Hospital, Southampton, SO14 0YG, ${ }^{2}$ Department of \\ Psychological Medicine, St Bartholomew's Hospital, London, EC1A 7BE, ${ }^{3}$ Clinical Pharmacology Group, \\ Southampton General Hospital, SO9 4XY \& ${ }^{4}$ Clinical Research Department, Sanofi Winthrop, Guildford, \\ GU1 4YS, UK.
}

1 A double-blind, multicentre study comparing the efficacy and safety of minaprine and amitriptyline in patients with major depression was carried out. Five hundred and thirty-one patients were randomly assigned to treatment with either minaprine $100 \mathrm{mg}, 200 \mathrm{mg}$ or $300 \mathrm{mg} \mathrm{day}^{-1}$ or with amitriptyline $150 \mathrm{mg} \mathrm{day}^{-1}$ ( $75 \mathrm{mg}$ during the first week). The medication was administered for 6 weeks.

3 Efficacy was assessed using the Hamilton rating scale for depression (HDRS), the Montgomery-Åsberg depression rating scale (MADRS) and visual analogue assessments of depression carried out by both the investigators and patients. Unwanted effects were assessed by a questionnaire and spontaneous reporting. In a subgroup of patients cardiovascular effects were investigated by high speed ECG and systolic time intervals.

3 Patients in each treatment group showed a significant clinical improvement $(P<0.01)$ from baseline. The mean HDRS and MADRS scores adjusted for baseline differences, showed significantly less improvement in the minaprine $100 \mathrm{mg}$ once daily $(P<0.01)$ and the minaprine $300 \mathrm{mg}$ daily $(P<0.01)$ groups than in the amitriptyline group at both week 4 and week 6 . The MADRS score at week 4 suggested that $200 \mathrm{mg} \mathrm{day}^{-1}$ minaprine was less effective than amitriptyline $(P<0.05)$, but there was no difference between the two groups at week 6 on either the HDRS or the MADRS.

4 Both drugs were well tolerated and there were no significant differences between treatment groups in any of the safety and tolerance assessments. In the ECG, amitriptyline produced a significant increase in the heart rate and PR interval while minaprine had no effect on electrocardiographic measurements. Neither drug produced changes in the systolic time intervals.

Keywords minaprine amitriptyline depression efficacy unwanted effects safety electrocardiography systolic time intervals

\begin{abstract}
Introduction
Minaprine dihydrochloride is an amino-phenylpyridazine that was first synthesised almost 25 years ago by Wermuth \& Exinger [1]. Neurochemical studies in the rat and mouse have shown that it facilitates serotonergic and dopaminergic neurotransmission, but does not affect noradrenergic transmission [2-5]. The drug is devoid of anticholinergic properties but induces some cholinomimetic effects [6].
\end{abstract}

\footnotetext{
Minaprine is rapidly and completely absorbed after oral administration in man. Pharmacokinetic studies in healthy volunteers have shown an extensive 'first-pass' effect after oral administration [7]. The major excreted metabolite of minaprine is its para-hydroxylated derivative, CM 30366. Peak plasma concentrations of the parent drug and its metabolites are reached about $1 \mathrm{~h}$ after oral intake following an overnight fast.

In doses of $50 \mathrm{mg}$ to $300 \mathrm{mg}$ day $^{-1}$ minaprine is well tolerated and has an antidepressant effect similar to
} 
imipramine, maprotiline and nomifensine [8-14]. It is devoid of significant anticholinergic side effects and standard speed ECGs have failed to demonstrate any significant cardiovascular effects $[12,15]$. The most frequently reported adverse effects - 'nervous tension', irritability and difficulty getting to sleep - could be due to its stimulant properties. Minor gastrointestinal symptoms have also been reported.

The present study was designed to compare the efficacy, safety and cardiac effects of three doses of minaprine with that of amitriptyline in patients with major depression.

\section{Methods}

The study was a prospective, randomised, double-blind, dose-ranging, multicentre trial in patients with major depression (DSM III-R, 16). Ratings of efficacy and unwanted effects were carried out by 52 consultant psychiatrists based in 42 hospitals throughout the United Kingdom and the Republic of Ireland. The cardiac investigations were carried out in Southampton.

\section{Patients}

Men and women who were not pregnant, lactating or liable to become pregnant during the trial, aged between 18 and 70 years, were considered for entry into the study. As well as meeting the DSM III-R criteria, they were required to have a minimum baseline score of 17 on the 17-item Hamilton rating scale for depression (HDRS; [17]).

Exclusion criteria were schizophrenia, an organic brain syndrome or epilepsy; serious suicidal tendencies; excessive alcohol consumption; diseases such as glaucoma and severe prostatic hypertrophy in which amitriptyline is contraindicated or should be used cautiously; clinical or laboratory evidence of significant hepatic, renal or cardiac disease; peptic ulceration; and treatment with lithium within the preceding 14 days or electroconvulsive therapy within the past 4 weeks.

The protocol was approved by each investigator's local ethics committee and patients gave written informed consent to participate in the study.

\section{Treatment}

There was an initial 4-7 day, single-blind washout under placebo cover. Those patients who did not respond to the placebo and who fulfilled the inclusion criteria were then randomly allocated to either minaprine $100 \mathrm{mg}$ once daily, minaprine $100 \mathrm{mg}$ twice daily, minaprine $300 \mathrm{mg}$ daily $(200 \mathrm{mg}$ in the morning and $100 \mathrm{mg}$ in the evening) or amitriptyline $50 \mathrm{mg}$ three times daily $(25 \mathrm{mg}$ three times daily during the first week). Medication was administered for 6 weeks. No other psychotropic drugs were allowed except temazepam $10-20 \mathrm{mg}$ as a hypnotic if really necessary. The dose, timing, duration and reasons for taking other drugs such as analgesics and laxatives were recorded.

\section{Assessments}

Patients meeting the inclusion criteria had a full medical examination, an ECG and a battery of haematological and biochemical laboratory tests.

The following assessments were carried out at the end of the placebo period and weekly thereafter during the 6 weeks of the study:

1 HDRS [17; an analysis of the factors described by Cleary \& Guy, [18] was carried out on the data)

2 Montgomery-Asberg depression rating scale (MADRS, [19])

3 Assessments of depression carried out by both physician and patient using a visual analogue scale ranging from 'not depressed at all' to 'extremely depressed'

4 Unwanted effects recorded by questionnaire and spontaneous reporting

5 Pulse rate and standing and supine blood pressure

Laboratory safety tests were carried out at baseline, weeks 4 and 6 or at the time of withdrawal or dropout. Returned capsule counts and plasma drug and metabolite concentrations were used as a measure of compliance. In such a large study carried out in many centres it was not possible to standardise the time of drug sampling, so the presence of drug was accepted as an indication of compliance.

Cardiac investigations were carried out in a subgroup of 28 patients, 18 of whom received minaprine and 10 amitriptyline. Measurements were made by a single observer at the end of placebo run-in and after 4 weeks treatment. High speed electrocardiograms were recorded at $100 \mathrm{~mm} \mathrm{~s}^{-1}$ and average measurements from five complexes were calculated. The QT interval was corrected for heart rate using standard methods [20]. Systolic time intervals were derived from simultaneous high speed recordings of the electrocardiogram $\left(100 \mathrm{~mm} \mathrm{~s}^{-1}\right)$, carotid pulse wave and phonocardiogram (SE oscillograph 3006/DL, UV recorder). Averages of the measurement of 10 consecutive beats, and the left ventricular ejection time and total electromechanical systole corrected for heart rate [21] were calculated. The pre-ejection period was not corrected for heart rate [22].

\section{Statistical analyses}

The required sample size was calculated using the method of Cochrane \& Cox [23]. Assuming that amitriptyline would produce a therapeutic response (defined as a $50 \%$ reduction in the HDRS score) in $70 \%$ of patients, 125 patients per group would have $90 \%$ power to detect a significant difference $(P<0.05)$.

For the total HDRS and MADRS scores, HDRS factors and visual analogue assessments of depression, analysis of covariance was used to assess treatment group differences and Dunnett's multiple comparison 
method [24] was used to compare the amitriptyline group with each of the minaprine groups. The age and sex of the patients and baseline HDRS or MADRS scores were used as covariates. Differences between the baseline and each assessment were analysed by comparing the difference in scores with zero using Student's $t$-test.

For the analyses, patients withdrawn before the end of the study were assumed to have maintained their last measured score at subsequent assessment intervals. The last score was also substituted for missing scores. The proportions of patients who were prematurely withdrawn from the treatment groups were compared using the Mantel-Haenzel chi-square test.

The incidence of spontaneously reported unwanted effects and symptoms elicited by the questionnaire was also compared using the Mantel-Haenzel chi-square test, controlled for whether the symptoms were present prior to treatment.

Treatment effects on laboratory parameters were assessed using a one-way analysis of covariance. Only those patients with a pre-treatment assessment and at least one post-treatment assessment were included in the analysis. Data from the serum alkaline phosphatase, bilirubin, alanine aminotransferase (ALT), aspartate aminotransferase (AST), gamma-glutamyltranspeptidase (GGT) and glucose estimations were highly skewed and therefore log-transformed prior to analysis.

Within-group and cardiac measurements were analysed by the paired Student's $t$-test and between group measurements by the unpaired Student's $t$-test. The results are presented as the mean \pm s.d.

\section{Results}

Five hundred and thirty one patients were recruited into the study. The numbers of men and women included in each of the four treatment groups together with the mean ages $( \pm$ s.d.) and previous psychiatric history are shown in Table 1 . One hundred and thirty three patients $(25.0 \%)$ failed to complete the 6 weeks of treatment.

The baseline ratings of severity of depression were similar in each group. The use of concomitant medication was also similar. Temazepam was taken by 66 patients prescribed minaprine $100 \mathrm{mg}, 72$ prescribed minaprine $200 \mathrm{mg}$ and 74 prescribed minaprine $300 \mathrm{mg}$ day $^{-1}$ compared with 61 patients given amitriptyline.

\section{Efficacy}

Prior to treatment with amitriptyline, the mean HDRS score was 25.2 (s.d.=5.0). This fell to $13.7( \pm 7.7)$ at week 4 and to $10.8( \pm 7.8)$ at week 6 . The baseline MADRS score in the amitriptyline group was 34.6 $( \pm 6.0)$, falling to $18.6( \pm 10.9)$ at week 4 and 15.2 $( \pm 10.9)$ at week 6 . All of these reductions were statistically significant $(P<0.01)$. Analysis of the HDRS and MADRS scores, adjusted for baseline differences for each group, showed that minaprine $300 \mathrm{mg}$ daily was significantly less effective than amitriptyline at week $4(P<0.01)$ and week $6(P<0.01$; see Table 2$)$. Minaprine $100 \mathrm{mg}$ once daily was also significantly less effective than amitriptyline, as determined by the MADRS at both week $4(P<0.05)$ and week $6(P<0.05)$. Analysis of the mean MADRS scores indicated that at week 4 minaprine $100 \mathrm{mg}$ twice daily was significantly less effective than amitriptyline. However, the difference between the groups was no longer statistically significant at week 6. The HDRS failed to show any statistically significant differences between the minaprine $200 \mathrm{mg}$ daily group and the amitriptyline group.

A breakdown of the HDRS into the four factors described by Cleary \& Guy [18] showed that minaprine $100 \mathrm{mg}$ once daily and $100 \mathrm{mg}$ twice daily were not significantly different from amitriptyline in respect of effects on 'anxiety/somatisation', 'cognitive disturbance'

Table 1 Sex, age and number of previous episodes of depression

\begin{tabular}{|c|c|c|c|c|}
\hline & $\begin{array}{c}\text { Minaprine } \\
100 \text { mg once } \\
\text { daily } \\
\mathrm{n}=134\end{array}$ & $\begin{array}{c}\text { Minaprine } \\
100 \text { mg twice } \\
\text { daily } \\
\mathrm{n}=133\end{array}$ & $\begin{array}{c}\text { Minaprine } \\
300 \mathrm{mg} \text { daily } \\
\mathrm{n}=132\end{array}$ & $\begin{array}{c}\text { Amitriptyline } \\
50 \mathrm{mg} \text { three } \\
\text { times daily } \\
\mathrm{n}=132\end{array}$ \\
\hline Male & 44 & 53 & 50 & 61 \\
\hline Female & 90 & 80 & 82 & 71 \\
\hline Ratio F:M & $2.0: 1$ & $1.5: 1$ & $1.6: 1$ & $1.2: 1$ \\
\hline \multicolumn{5}{|l|}{ Mean age (years) } \\
\hline $\begin{array}{l}\text { Male } \\
\text { (Range) }\end{array}$ & $\begin{array}{c}44.2 \\
(21-67)\end{array}$ & $\begin{array}{c}45.1 \\
(21-68)\end{array}$ & $\begin{array}{c}46.2 \\
(20-70)\end{array}$ & $\begin{array}{c}41.0 \\
(18-69)\end{array}$ \\
\hline $\begin{array}{l}\text { Female } \\
\text { (Range) }\end{array}$ & $\begin{array}{c}45.9 \\
(21-71)\end{array}$ & $\begin{array}{c}47.0 \\
(17-74)\end{array}$ & $\begin{array}{c}46.8 \\
(22-70)\end{array}$ & $\begin{array}{c}46.3 \\
(23-72)\end{array}$ \\
\hline \multicolumn{5}{|l|}{ Previous episodes } \\
\hline $\begin{array}{l}\text { Number of patients } \\
\text { (percentage) }\end{array}$ & $\begin{array}{l}92 \\
(68.7)\end{array}$ & $\begin{array}{l}84 \\
(63.2)\end{array}$ & $\begin{array}{l}80 \\
(60.6)\end{array}$ & $\begin{array}{l}82 \\
(62.1)\end{array}$ \\
\hline
\end{tabular}


Table 2 Mean baseline HDRS and MADRS scores and differences in scores between minaprine and amitriptyline groups at week 4 and week 6 (95\% confidence intervals)

\begin{tabular}{lcccc}
\hline & $\begin{array}{c}\text { Minaprine } \\
100 \mathrm{mg} \text { once } \\
\text { daily }\end{array}$ & $\begin{array}{c}\text { Minaprine } \\
100 \mathrm{mg} \text { twice } \\
\text { daily }\end{array}$ & $\begin{array}{c}\text { Minaprine } \\
300 \mathrm{mg} \text { daily }\end{array}$ & $\begin{array}{c}\text { Amitriptyline } \\
50 \mathrm{mg} \text { three } \\
\text { times daily }\end{array}$ \\
\hline $\begin{array}{l}\text { HDRS scores } \\
\text { Baseline }\end{array}$ & & & \\
Week 4 & 25.4 & 24.8 & 25.7 & 25.2 (s.d. 5.0) \\
& 1.9 & 2.0 & $3.9^{* *}$ & 13.7 (s.d. 7.7) \\
Week 6 & $(-0.4-4.2)$ & $(-0.2-4.4)$ & $(1.7-6.2)$ & \\
& $2.6^{*}$ & 2.4 & $3.6^{* *}$ & 10.8 (s.d. 7.8) \\
MADRS scores & $(0.0-5.2)$ & $(-2.1-4.9)$ & $(1.0-6.1)$ & \\
Baseline & & & \\
Week 4 & 33.2 & 32.6 & 32.5 & 34.6 (s.d. 6.0) \\
& $3.3^{*}$ & $3.9^{* *}$ & $5.6^{* *}$ & 18.6 (s.d. 10.9) \\
Week 6 & $(0.3-6.3)$ & $(0.9-6.9)$ & $(2.6-8.7)$ & \\
& $5.0^{*}$ & 3.2 & $4.1^{* *}$ & 15.2 (s.d. 10.9) \\
\hline
\end{tabular}

*Significant difference from amitriptyline $P<0.05$ (Dunnet's test)

**Significant difference from amitriptyline $P<0.01$ (Dunnet's test)

s.d. Standard deviation

Table 3 Mean baseline physician and patient depression assessment scores and differences in scores between minaprine and amitriptyline groups at week 4 and week 6 (95\% confidence intervals)

\begin{tabular}{lcccc}
\hline & $\begin{array}{c}\text { Minaprine } \\
\text { 100 } \begin{array}{c}\text { mg once } \\
\text { daily }\end{array}\end{array}$ & $\begin{array}{c}\text { Minaprine } \\
100 \mathrm{mg} \text { twice } \\
\text { daily }\end{array}$ & $\begin{array}{c}\text { Minaprine } \\
300 \mathrm{mg} \text { daily }\end{array}$ & $\begin{array}{c}\text { Amitriptyline } \\
50 \mathrm{mg} \text { three } \\
\text { times daily }\end{array}$ \\
\hline $\begin{array}{l}\text { Physician assessment } \\
\text { Baseline }\end{array}$ & & & \\
Week 4 & 64.5 & 61.8 & 63.1 & 63.6 (s.d. 15.5) \\
& 5.4 & 4.7 & $8.0^{*}$ & 38.2 (s.d. 25.4) \\
Week 6 & $(-1.2-12.0)$ & $(-1.9-11.3)$ & $(1.3-14.6)$ & \\
& 6.6 & 4.7 & $9.2^{*}$ & 31.0 (s.d. 25.8) \\
Patient assessment & $(-0.9-14.2)$ & $(-2.8-12.3)$ & $(1.7-16.8)$ & \\
Baseline & & & \\
Week 4 & 66.0 & 65.8 & 65.3 & 68.5 (s.d. 17.3) \\
Week 6 & $8.0^{*}$ & 7.0 & $10.8^{* *}$ & 42.0 (s.d. 27.2) \\
& $(0.4-15.6)$ & $(-0.7-14.7)$ & $(3.1-18.6)$ & \\
& 8.2 & 6.0 & $9.8^{*}$ & 36.0 (s.d. 28.4) \\
\hline
\end{tabular}

*Significant difference from amitriptyline $P<0.05$ (Dunnet's test)

**Significant difference from amitriptyline $P<0.01$ (Dunnet's test)

or 'retardation'. These two doses of minaprine were, however, significantly less effective than amitriptyline in the treatment of 'sleep disturbance' $(P<0.01)$. The minaprine $300 \mathrm{mg}$ daily dose was significantly less effective than amitriptyline on all four factors $(P<0.05)$.

The mean visual analogue assessment of depression recorded by both physician and patient were adjusted for baseline differences and are shown in Table 3. In each treatment group there was a significant reduction from baseline scores $(P<0.01)$, but patients treated with minaprine $300 \mathrm{mg}$ daily did not respond as well as those who received amitriptyline $(P<0.01)$.
Safety

A total of 287 alleged unwanted effects occurring on active medication were reported spontaneously. More effects were reported by patients in the amitriptyline group than in the individual minaprine groups. The most common effects are shown in Table 4. No statistically significant differences were found between the treatment groups in the numbers of patients who reported dizziness, headache and dry mouth. The number of patients reporting other symptoms was too small for a meaningful statistical analysis. 
Table 4 Frequency of spontaneously reported unwanted effects

\begin{tabular}{|c|c|c|c|c|}
\hline & $\begin{array}{c}\text { Minaprine } \\
100 \text { mg once } \\
\text { daily }\end{array}$ & $\begin{array}{c}\text { Minaprine } \\
100 \mathrm{mg} \text { twice } \\
\text { daily }\end{array}$ & $\begin{array}{c}\text { Minaprine } \\
300 \mathrm{mg} \text { daily }\end{array}$ & $\begin{array}{c}\text { Amitriptyline } \\
50 \mathrm{mg} \text { three } \\
\text { times daily }\end{array}$ \\
\hline $\begin{array}{l}\text { Patients reporting } \\
\text { unwanted effects } \\
(\%)\end{array}$ & $\begin{array}{c}34 \\
(25.4)\end{array}$ & $\begin{array}{c}33 \\
(24.8)\end{array}$ & $\begin{array}{c}43 \\
(32.6)\end{array}$ & $\begin{array}{c}47 \\
(35.6)\end{array}$ \\
\hline Somnolence & 0 & 1 & 2 & 8 \\
\hline Dizziness & 5 & 1 & 8 & 12 \\
\hline Headache & 4 & 4 & 10 & 4 \\
\hline Dry mouth & 3 & 2 & 3 & 15 \\
\hline Nausea & 6 & 3 & 10 & 0 \\
\hline Vomiting & 3 & 2 & 4 & 2 \\
\hline Rash & 2 & 3 & 4 & 1 \\
\hline Other & 40 & 34 & 37 & 54 \\
\hline Total & 63 & 50 & 78 & 96 \\
\hline
\end{tabular}

Note: An unwanted effect reported by one patient on more than one occasion is included only once in the total.

Table 5 Frequency of symptoms reported by the drug safety and tolerance questionnaire

\begin{tabular}{lcccc}
\hline & $\begin{array}{c}\text { Minaprine } \\
100 \mathrm{mg} \text { once } \\
\text { daily }\end{array}$ & $\begin{array}{c}\text { Minaprine } \\
100 \mathrm{mg} \text { twice } \\
\text { daily }\end{array}$ & $\begin{array}{c}\text { Minaprine } \\
300 \mathrm{mg} \text { daily }\end{array}$ & $\begin{array}{c}\text { Amitriptyline } \\
50 \text { mg three } \\
\text { times daily }\end{array}$ \\
\hline Drowsiness & 23 & 37 & 29 & $41^{*}$ \\
Memory impairment $\$$ & 15 & 10 & 13 & $23^{* *}$ \\
Increased apprehension & 10 & 19 & 20 & $6^{*}$ \\
Difficulty falling asleep & 11 & 8 & 7 & $2^{*}$ \\
Increased appetite & 20 & 13 & 16 & $31^{*}$ \\
Dry mouth & 23 & 33 & 34 & $47^{*}$ \\
Dysuria & 5 & 9 & 8 & $17^{* *}$ \\
\hline
\end{tabular}

§Subjective memory impairment

*Significant difference minaprine $v$ s amitriptyline $(P<0.05-$ Mantel-Haenzel's test $)$

**Significant difference minaprine $v s$ amitriptyline $(P<0.01-$ Mantel-Haenzel's test $)$

The symptoms most frequently elicited with the drug safety and tolerance questionnaire are shown in Table 5. Drowsiness, subjective memory impairment, increased appetite, dry mouth and urinary hesitancy were each found significantly more often in the amitriptyline treated group $(P<0.05)$. Symptoms reported more frequently by the minaprine treated patients were increased apprehensiveness and difficulty falling asleep. Slightly more patients in the minaprine $300 \mathrm{mg}$ daily group reported unwanted effects that were rated as 'severe' by the investigators (minaprine $100 \mathrm{mg}-5$; minaprine $200 \mathrm{mg}$ - 6; minaprine $300 \mathrm{mg}$ - 9; amitriptyline-6). There were no significant between-group differences in pulse rate or blood pressure.

One patient in each of the minaprine $100 \mathrm{mg}$ twice daily and minaprine $300 \mathrm{mg}$ daily groups committed suicide. The first, a 69 year old man with a long history of recurrent depression, drowned himself after completing 4 weeks treatment as an in-patient. The second, a 51 year old man who had had suicidal thought prior to entering the study, hanged himself after 4 weeks treatment with minaprine $300 \mathrm{mg} \mathrm{day}^{-1}$.

There were six known instances of self-poisoning (one each in the minaprine $100 \mathrm{mg}$ once daily and amitriptyline groups and two each in the minaprine $100 \mathrm{mg}$ twice daily and minaprine $300 \mathrm{mg}$ groups), but only two patients took overdoses of minaprine. The first of these took unknown quantities of minaprine and paracetamol together with an excess of alcohol. The other took nine capsules containing up to $1.8 \mathrm{~g}$ of minaprine with approximately $30 \mathrm{~g}$ of paracetamol, $240 \mathrm{mg}$ of codeine and $28300 \mathrm{mg}$ aspirin tablets. Each patient made a complete and uneventful recovery.

Routine laboratory investigations revealed a number of clinically significant results that were considered to be related to treatment. Two patients (one on minaprine $100 \mathrm{mg}$ twice daily and the other taking amitriptyline) were withdrawn from the study because of raised liver function tests. The patient receiving minaprine showed a marked increase (3-8 times the upper limit of the normal range) in AST, ALT and GGT after 4 weeks of treatment. Serum ALT and GGT levels one and a half times the upper limit of normal were reported in the patient on amitriptyline. Two patients were withdrawn because of haematological abnormalities. The white blood cell count of one patient, who received minaprine 
$100 \mathrm{mg}$ once daily, fell to $3.9 \times 10^{9} 1^{-1}$, while that of the other, who had taken minaprine $300 \mathrm{mg}$ daily, fell to $2.6 \times 10^{9} 1^{-1}$.

\section{Withdrawals}

One hundred and thirty-three patients were withdrawn from the study; the reasons for withdrawal are shown in Table 6. Adverse events leading to withdrawal included the reappearance of persecutory delusions in a patient who had previously had these experiences (the patient was in the minaprine $100 \mathrm{mg}$ twice daily group) and the occurrence of auditory hallucinations in another who was taking minaprine $300 \mathrm{mg}$ daily. A third patient, a 25 year old woman with no previous history of epilepsy, had a grand mal seizure 2 days after starting treatment with minaprine $300 \mathrm{mg}$ day $^{-1}$. EEGs carried out 4 days after the seizure and 6 months later each revealed spike activity showing that she was predisposed to epilepsy.

\section{Compliance}

Plasma drug concentrations were measured in 305 $(79.6 \%)$ of the patients included in the study and parent drug or metabolites were detected in $275(90.2 \%)$ of these. This, taken in conjunction with good matching between the capsule counts of drugs prescribed and returned, suggests that compliance was satisfactory.

\section{Cardiac investigations}

Satisfactory electrocardiograms were obtained from 28 patients recruited in Southampton. Of those receiving minaprine, five were taking $100 \mathrm{mg}$ daily, seven $200 \mathrm{mg}$ daily and six $300 \mathrm{mg}$ daily. There were no dose-related trends in the results. Satisfactory systolic time intervals were obtained on both occasions in all patients receiving minaprine and eight patients receiving amitriptyline.

There were no significant between-group differences in the electrocardiograms at baseline (Table 7). Minaprine had no effects on electrocardiographic measurements, while amitriptyline significantly increased the heart rate, shortening the sinus cycle length by an average of $19 \%(P=0.002)$; amitriptyline also prolonged the PR interval by an average of $3.4 \%(P=0.04)$. The systolic time intervals at baseline were similar in the two groups of patients, and neither drug produced any significant changes.

\section{Discussion}

Like all research, multicentre trials have their strengths and weaknesses. Foremost among the former is the ability to recruit much larger numbers of patients than is possible in a single centre. Disadvantages include the difficulty in assembling a team of investigators who, or whose ethics committees, are agreeable to using a placebo control, greater heterogeneity in the patients included and problems in achieving good inter-rater reliability in the use of rating scales. The inclusion of a placebo control can be safe and ethical, so long as adequate precautions are taken [25], while not having such a control means that antidepressant effects cannot be confidently demonstrated. Non-placebo controlled trials can, however, reveal differences in effectiveness and unwanted effects between different drugs and different doses. With regard to the present study, advantages of minaprine over placebo have previously been demonstrated by Jouvent et al. [26] and Amsterdam et al. [27].

Our results suggest that minaprine $100 \mathrm{mg}$ and $300 \mathrm{mg}$ day $^{-1}$ are less effective than amitriptyline $150 \mathrm{mg} \mathrm{day}^{-1}$ in the treatment of major depression. This is conceivably due to the existence of a therapeutic window as has

Table 6 Summary of reasons for withdrawal by treatment group

\begin{tabular}{lcccc}
\hline & $\begin{array}{c}\text { Minaprine } \\
100 \mathrm{mg} \text { once } \\
\text { daily }\end{array}$ & $\begin{array}{c}\text { Minaprine } \\
100 \mathrm{mg} \text { twice } \\
\text { daily }\end{array}$ & $\begin{array}{c}\text { Minaprine } \\
300 \mathrm{mg} \text { daily }\end{array}$ & $\begin{array}{c}\text { Amitriptyline } \\
50 \mathrm{mg} \text { three } \\
\text { times daily }\end{array}$ \\
\hline Non-compliance & 3 & 6 & 3 & 4 \\
Lack of efficacy & 3 & 4 & 4 & 3 \\
Unwanted effects & 8 & 9 & 16 & 12 \\
Drop-out & 10 & 8 & 8 & 6 \\
Loss to follow-up & 3 & 3 & 2 & 0 \\
Overdose & 1 & 2 & 2 & 1 \\
Suicide & 0 & 1 & 3 & 0 \\
Other§ & 7 & 0 & 0 & 2 \\
Not recorded & 2 & 33 & 39 & 25 \\
Total & 36 & & & 0 \\
\hline
\end{tabular}

Note: Some patients were withdrawn for more than one reason. In these cases all reasons for withdrawal have been included.

§The category 'Other' includes intercurrent illness and marked improvement 
Table 7 Effects of minaprine and amitriptyline on the electrocardiogram and systolic time intervals

\begin{tabular}{lcccc}
\hline & \multicolumn{2}{c}{ Minaprine } & \multicolumn{2}{c}{ Amitriptyline } \\
& Baseline & Week 4 & Baseline & Week 4 \\
\hline QS $_{2}$ I & $531 \pm 39$ & $527 \pm 36$ & $529 \pm 32$ & $541 \pm 33$ \\
LVET1 & $436 \pm 31$ & $424 \pm 36$ & $416 \pm 27$ & $413 \pm 27$ \\
PEP & $66 \pm 51$ & $77 \pm 49$ & $86 \pm 11$ & $94 \pm 32$ \\
PEP/LVET1 ratio & $0.16 \pm 0.13$ & $0.19 \pm 0.12$ & $0.21 \pm 0.03$ & $0.23 \pm 0.08$ \\
SCL (ms) & $795 \pm 142$ & $824 \pm 127$ & $772 \pm 109$ & $625 \pm 83^{\dagger}$ \\
PR-interval (ms) & $152 \pm 20$ & $151 \pm 16$ & $146 \pm 19$ & $151 \pm 21^{*}$ \\
QRS-duration (ms) & $87 \pm 12$ & $86 \pm 9$ & $86 \pm 12$ & $89 \pm 16$ \\
QT & $417 \pm 18$ & $424 \pm 22$ & $406 \pm 19$ & $414 \pm 15$ \\
\hline
\end{tabular}

Measurements are mean \pm standard deviation.

$\mathrm{QS}_{2} \mathrm{I}$, LVET1 are respectively the duration of electromechanical systole and the left ventricular ejection time corrected for heart rate. PEP is the pre-ejection period

$\mathrm{SCL}$ is the sinus cycle length

$\mathrm{QT}_{\mathrm{C}}$ is the QT interval corrected for heart rate

$\dagger P=0.002$ compared with baseline

$* P=0.04$ compared with baseline

previously been shown with zimeldine [28] and fluoxetine $[29,30]$. The lower effectiveness of minaprine $300 \mathrm{mg}$ day $^{-1}$ could be due to a dysphoric effect, although this was not obvious from open-ended questions in the safety and tolerance questionnaire. If a 'therapeutic window' does exist, it could be due to a complex interplay between efficacy and unwanted effects. A breakdown of the HDRS scores into the factors described by Cleary \& Guy [18] produced results consistent with the lack of sedative-like symptoms with minaprine in the doses used while the MADRS, which is thought to be less biased than the HDRS towards somatic symptoms of depression, appears more sensitive to treatment differences.

The numbers of patients in the four treatment groups who experienced specific unwanted effects were too small for a meaningful statistical analysis, but sedativetype symptoms and anticholinergic-like effects, especially dry mouth and dysuria, occurred in more patients treated with amitriptyline, whereas 'stimulant' effects (increased apprehension and sleep disturbance) were encountered more often in those treated with minaprine.

Therapeutic doses of tricyclic antidepressants have been shown to have unwanted effects on cardiovascular function [31-35]. In overdose, these effects are particularly marked and include conduction disturbances, tachyarrhythmias, myocardial depression and postural hypotension [36, 37]. Many newer antidepressants have less pronounced effects on the heart which could make them safer than tricyclics when taken in overdose or when administered to patients with pre-existing cardiovascular disease.

The changes in the electrocardiogram produced by amitriptyline in the present study were consistent with those previously reported [35, 38, 39]. Minaprine did not have any significant effects and, in contrast to amitriptyline, showed a trend towards slowing of the heart rate. Although therapeutic doses of amitriptyline has been reported to reduce myocardial contractility $[40,41]$, this has not been a universal finding [35] and was not detected in the current study. Similarly, minaprine did not affect the systolic time intervals. Our findings suggest that minaprine has little effect on myocardial function in therapeutic doses. The ECG changes produced by amitriptyline are similar to, although less marked than, those found following overdoses. The absence of an increase in heart rate or prolongation of the PR interval during treatment with minaprine suggests that this drug is less likely than amitriptyline to produce sinus bradycardia or conduction defects in overdose, although the risk of ventricular tachycardia cannot be predicted. The effects of higher doses of minaprine would need to be measured to confirm these findings.

We would like to acknowledge the contribution of the psychiatrists who took part in this study, Julia Brown and Nigel Brayshaw who provided statistical support, and Sanofi Winthrop for the generous grant that made the study possible.

\section{References}

1 Wermuth CG, Exinger A. Le dichlorhydrate de la morpholinoethylamino-3-methy-4-phenyl-6-pyridazine. Agressologie 1972; 13: 285-289.

2 Bizière K, Kan JP, Goniot S, Wermuth CG. Neurochemical profile of a novel psychotropic drug. J Neurochem 1983; 41: 78-82.

3 Kan JP, Baudry N, Bougault I, Gonalons S, Garratini S. Effets de la minaprine $\left(\right.$ Cantor $\left.^{\circledR}\right)$ sur la transmission dopaminergique centrale chez le rongeur. Acta Pharm Biol Clin 1983; 2: 137-142.

4 Ferreti $\mathrm{P}$, Algeri S, Benefati F, Cimino M, Ferreti L. Chemical effects of minaprine on striatal dopaminergic neurons in rats. J Pharm Pharmacol 1984; 36: 48-52.

5 Garattini SM Forloni GL, Tirelli AS, Ladinski $H$, Consolo S. Neurochemical effect of minaprine, a novel psychotropic drug, on the central cholinergic system of the rat. Psychopharmacology 1984; 82: 210-215.

6 Worms P, Kan JP, Steinberg R, Terranova J-P, Perio A, 
Bizière K. Cholinomimetic activities of minaprine. Arch Pharmacol 1989; 340: 411-418.

7 Davi H, Dupont P, Jeanniot JP, Roncucci R, Cautreels W. The biotransformation of 14C-minaprine in man and five animal species. Xenobiotica 1985; 15: 97-106.

8 Crocq L, Fondarai J, Haniin B. The place of minaprine in general practice. Psychol Med 1982; 14: 1097-1116.

9 Mariani E, Francheschi M, Minicucci F, Strambi LF, Smirne S. Therapeutic efficacy of minaprine and nomifensine in neurotic depression. Clin Neurol 1983; 4: 165-168.

10 Mikus $\mathrm{P}$, Bizière $\mathrm{K}$, Bentel U. A controlled study of minaprine and nomifensine in outpatients with masked depression. Clin Trials J 1985; 22: 477-488.

11 Radmayr E, Bizière K, Bentel U. Minaprine and maprotiline in endogenous depression: A double-blind controlled study. Clin Trials $J$ 1986; 23: 100-109.

12 Bohacek N, Ravic M, Bizière K. Minaprine and imipramine in the treatment of major depressive disorders. A comparative double-blind study. Drugs Exp Clin Res 1987; 7: 435-442.

13 Montgomery SA, Baldwin DS, Priest RG, et al. Minaprine and dose response in depression: An investigation of two fixed doses of minaprine compared with imipramine. Pharmacopsychiatry 1991; 24: 168-174.

14 Wheatley D. Minaprine in depression. A controlled trial with amitriptyline. Br J Psychiat 1992; 161: 113-115.

15 Smirne S, Mariani E, Tancredi D, Francheschi M, Canal N. Effects of minaprine on sleep, anxiety and cognitive functions. Clin Trials $J$ 1985; 22: 187-200.

16 American Psychiatric Association Diagnostic and Statistical Manual of Mental Disorder. 3rd Edition Revised. Washington DC, American Psychiatric Association, 1987: 218-224.

17 Hamilton M. Development of a rating scale for primary depressive illness. Br J Soc Clin Psychol 1967; 6: 278-296.

18 Cleary P, Guy W. Factor analysis of the Hamilton depression scale. Drugs Exp Clin Res 1977; I: 115-120.

19 Montgomery SA, Åsberg M. A new depression scale designed to be sensitive to change. Br J Psychiat 1979; 134: 382-389.

20 Bazett HC An analysis of the time-relationship of electrocardiograms. Heart 1920; 7: 353-370.

21 Lewis RP, Rittgers SE, Forester WF, Boudoulas H. A critical review of systolic time intervals. Circulation 1977; 56: $146-158$.

22 Sundberg S. Influence of heart rate on systolic time intervals. Am J Cardiol 1986; 58: 1144-1145.

23 Cochrane WG, Cox GM (1957). Experimental Designs. 2nd Edition. New York, Wiley, 1957.

24 Dunnett CW. A multiple comparisons procedure for comparing several treatments with a control. $J$ Am Stat Ass 1955; 50: 1096-1121.

25 Edwards JG. Ethics of placebo-controlled trials in depression. Human Psychopharmacol 1989; 4: 235-236.
26 Jouvent R, Lancrenon S, Patay M, Widlocher D. A controlled trial of minaprine versus placebo in inhibited depressed outpatients. In Recent Advances in Psychiatric Treatment, First European Conference 1984; p3.

27 Amsterdam JD, Dunner DL, Fabre LF, Kiev A, Rush AJ, Goodman LI. Double-blind, placebo controlled, fixed dose trial of minaprine in patients with major depression. Pharmacopsychiat 1989; 22: 137-143.

28 Montgomery SA, McAuley R, Rani SJ, Roy D, Montgomery D. A double blind comparison of zimelidine and amitriptyline in endogenous depression. Acta Psychiatr Scand 1981; 63 (suppl. 290): 314-327.

29 Wernicke JF, Dunlop SR, Dornseif BE, Zerbe RL. Fixed dose fluoxetine therapy of depression. Psychopharmacol Bull 1987; 23: 164-168.

30 Wernicke JF, Dunlop SR, Dornseif BE, Bosomworth JC, Humbert M. Low dose fluoxetine therapy for depression. Psychopharmacol Bull 1988; 24: 183-188.

31 Blackwell B. Adverse effects of antidepressant drugs. 1. Monoamine oxidase inhibitors and tricyclics. Drugs 1981; 21: 201-219.

32 Cassem N. Cardiovascular effects of antidepressants. J Clin Psychiat 1982; 43: 22-28.

33 Risch SG, Groom GP, Janowsy DS. The effects of psychotropic drugs on the cardiovascular system. $J$ Clin Psychiat 1982; 43: 16-31.

34 Veith RC, Raskind MA, Caldwell JH, Barnes RF, Gumbrecht G, Ritchie JL. Cardiovascular effects of tricyclic antidepressants in depressed patients with chronic heart disease. N Engl J Med 1982; 306: 954-959.

35 Upward JW, Edwards JG, Goldie A, Waller DG. Comparative effects of fluoxetine and amitriptyline on cardiac function. Br J Clin Pharmacol 1988; 26: 399-402.

36 Sacks MH, Bonforte RJ, Lasser RP, Dimich I. Cardiovascular complications of imipramine intoxication. JAMA 1968; 205: 588-590.

37 Cassidy S, Henry J. Fatal toxicity of antidepressant drugs in overdose. Br Med J 1987; 295: 1021-1024.

38 Nemec J. Cardiotoxic effects of tricyclic antipsychotics. Toxicol Exp 1973; 4-5: 224-231.

39 Fisch C. Effect of fluoxetine on the electrocardiogram. $J$ Clin Psychiat 1985; 46: 424-444.

40 Burgess CD, Montgomery S, Wadsworth J, Turner P. Cardiovascular effects of amitriptyline, mianserin, zimelidine and nomifensine in depressed patients. Postgrad Med J 1979; 55: 704-708.

41 Burgess CD, Turner P. Cardiovascular effects of antidepressants; clinical implications. In Stress and the Heart, ed. Wheatley D, New York, Raven: 1981: pp173-190.

(Received 9 October 1995, accepted 2 May 1996) 